\title{
ОТНОШЕНИЕ К ЧАЕПИТИЮ КАК МАРКЕР ПРОФЕССИОНАЛИЗАЦИИ СООБЩЕСТВА ТРЕТЬЕГО СЕКТОРА В САНКТ-ПЕТЕРБУРГЕ
}

На основе исследования «профессионализации» НКО- процесса бюрократизации, возникновения «экспертного знания» и сообщества третьего сектора - статья рассматривает распространение культуры чаепитий в России с точки зрения ее значения для деятельности НКО. Ставится вопрос о том, как культура потребления чая рассматривается в дискуссиях об активном долголетии (active ageing) и построении идентичности сообщества третьего сектора. Данные об отношении к чаепитиям получены в результате качественного социологического исследования $16 \mathrm{HKO}$, занимающихся оказанием негосударственной заботы и социальных услуг людям старшего возраста в Санкт-Петербурге. На основе полуструктурированных интервью, включенных наблюдений и анализа документов приводятся аргументы, свидетельствующие, что профессионализированные НКО- небольшое и относительно закрытое сообщество, связанное общими проектами, идеологией («активного старения») и представлениями об организационной деятельности, рассматривают чаепития через призму «бесполезности» для развития третьего сектора и «гражданской культуры» в России. Чаепития воспринимаются своеобразной оппозицией такой культуре, выступая в роли примера крайней степени «неэффективности», «неустойчивости», т.е. всего того, против чего выступают профессионализированные НКО. Основной темой статьи является место чаепития как социальной услуги в дискурсе о «хорошей заботе» среди НКО, оказывающих социальные услуги пожилым людям (на примере Санкт-Петербурга). Чаепитие в данном случае выступает характерной и распространенной формой социальных услуг, отношение к которой существенно отличается среди представителей НКО в зависимости от степени их вовлеченности в профессиональное сообщество. Сделан

Артур Холявин-M. Sc.Рol., докторант, Университет Хельсинки, Финляндия. Электронная почта: Holavins.A@tsi.lv 
вывод о том, что использование чаепитий (как социальных услуг для людей старшего возраста) в деятельности НКО является своеобразным водоразделом, по которому профессиональное сообщество третьего сектора судит о принадлежности или непринадлежности организаций третьего сектора к «профессиональному» сообществу. В заключении предлагаются несколько направлений для потенциальных исследований практик чаепития с точки зрения изучения гражданского общества и трансформации политической культуры.

Ключевые слова: чаепитие, гражданственность, НКО, идентичность, профессиональное сообщество

DOI: $10.17323 / 727-0634-2020-18-1-99-114$

\section{Введение}

Это исследование рассматривает отношение российских некоммерческих организаций (НКО) к чаепитию как форме проведения досуга пожилых людей. Отличия в восприятии чаепитий соответствуют разным представлениям НКО о том, какие формы социальных услуг являются предпочтительными для их подопечных (клиентов). Спектр представлений о чаепитиях варьируется от негативного («бесполезная трата времени», «неэффективно») до положительного («способ завести друзей», «семейная атмосфера»).

Как оказалось, различия в мнениях соответствуют различным формам действующих в Санкт-Петербурге НКО (поставщики социальных услуг, группы самопомощи, низовые инициативы, ветеранские организации) и в целом укладываются в логику «профессионализации» организаций третьего сектора (Jalali 2013; Shrestha, Adhikri 2011). Иными словами, отношение к чаепитию для представителей третьего сектора является своеобразным маркером принадлежности к сообществу НКО (или, наоборот, исключённости из него), а также- составной частью идентичности «профессионализированных» организаций. Стоит отметить, что понятие «гражданское общество» в статье не используется, так как рассматривается конкретная совокупность российских некоммерческих организаций.

Соответственно, основной темой статьи является место чаепития как социальной услуги в дискурсе о «хорошей заботе» среди НКО, оказывающих социальные услуги пожилым людям (на примере Санкт-Петербурга). Чаепитие в данном случае выступает характерной и распространенной формой социальных услуг. Отношение к нему существенно отличается среди представителей НКО в зависимости от степени их вовлеченности в профессиональное сообщество. Данное исследование позволяет лучше понять составные части идентичности, дискурса и, как следствие, практик, формирующих профессиональное сообщество третьего сектора в России. Иными словами, изучение дискурса о чаепитиях позволяет изучить процесс профессионализации НКО в России, так как критическое отношение к данной социальной 
услуге является важным аспектом культуры «гражданственности» и «профессионализма» петербургских НКО.

На основе вышеуказанной темы сформулирован исследовательский вопрос: каково восприятие чаепития как формы деятельности организациями третьего сектора в России? Предполагаемым ответом-гипотезами- стали следующие утверждения: (а) восприятие чаепития как «неустойчивой» и «бесполезной» практики является признаком «профессионализированной идентичности» НКО (Kreutzer, Jäger 2010); (б) восприятие чаепития как важной и неотъемлемой части негосударственной заботы о людях старшего возраста является признаком отсутствия «профессионализированной» идентичности.

Стоит отметить, что «чай» (или «чаепитие») изначально не упоминался в путеводителе для интервью. Однако оказалось, что многие представители профессионализированного третьего сектора сами поднимали тему чаепитий (как формы социализации), при сравнении своей деятельности с работой «непрофессиональных НКО». Информанты, представляющие «профессиональные» НКО, регулярно приводили в пример «чаепития», говоря о «неэффективных» формах заботы, и «имитации гражданского общества». В связи с этим я начал задавать «провокационный» вопрос: «Возможно, было бы лучше следовать пожеланиям самих получателей услуг и вместо сложных проектов просто устраивать чаепития?». Обычный ответ на этот вопрос звучал следующим образом:

[Возможно.] И тем не менее попить чай тоже должен подготовленный человек приходить. Потому что правильная реакция на слёзы должна быть, правильная реакция на «приходи завтра» и так далее, то есть, нельзя относиться к этой работе как к чему-то, устроенному по остаточному принципу или не требующему профессиональных навыков (Информант 2, женщина, около тридцати лет, проектный менеджер частного фонда-грантодателя). ${ }^{1}$

Мнение, как в приведённой цитате, разделяемое представителями большинства профессионализированных НКО, и стало отправной точкой для данного исследования.

\section{Построение идентичности профессионализированных НКО: теория}

Стоит пояснить, что понимается под «профессионализацией НКО» и в чём отличие «профессионализированных» НКО от «низовых». Существует достаточно обширный пласт литературы (напр., обзор Maier et al. 2016), рассматривающий то, как организации третьего сектора бюрократизируются, переориентируются на «экспертность» собственной деятель-

\footnotetext{
${ }^{1}$ Все имена и названия организаций анонимизированы.
} 
ности (Salamon 1999) и, в результате, «отрываются» от местного сообщества (Petrescu 2000: 233-34). Вместо представительства интересов граждан они начинают заниматься поддержанием собственного существования (King 2016; Krause 2014).

Большинство исследователей, изучающих «профессионализацию НКО» отмечают угрозу данного процесса демократической природе организаций третьего сектора (Choudry, Kapoor 2014). Как поясняет Рита Джалали (Jalali 2013: 61):

[всё] больше времени и усилий уходит на деятельность вроде написания грантовых заявок, поиск финансирования, бухучёт и годовые отчёты, отвлекая энергию и мотивацию организаций от [интересов и проблем] местного сообщества.

Этот процесс затрагивает не отдельные организации, а приводит к формированию профессионализированного «экспертного сообщества» мыслящих и действующих схожим образом организаций (Jalali 2013; Batley 2011). У членов такого сообщества с точки зрения деятельности организации возникает ряд общих признаков. Во-первых, их структура и деятельность усложняются, происходит «рост численности служащих и уровней иерархии <..> усложнение формальной регламентации деятельности» (Бабинцев 2014: 30). Профессионализирующиеся НКО начинают «утопать» в бумажной работе, вырабатывают строгие требования к собственной деятельности и «специализируются» (Jalali 2013: 60-62). Последнее напрямую связано с претензией на «экспертное знание» и придание значимости роли «профессионализма» (Scheba, Mustalahti 2015: 2; Nightingale 2005).

И бюрократизация, и экспертное знание связаны с «проектным» мышлением. Это такой организационный подход к деятельности, при котором всё мыслится в форме «проектов», т.е. со строго определёнными временными и логическими рамками, строгой отчётностью и с не менее строгими критериями оценки успешности. В крайних случаях организация отходит от стратегического мышления и начинает мыслить в категориях грантовых заявок, а получатели услуг превращаются в «цифры в отчёте» и своеобразный ресурс в отношениях с грантодателями (Krause 2014). Основной же целью существования профессионализированных НКО становится не оказание услуг, а поддержание собственной деятельности.

Наконец, я подхожу к основному фокусу своего исследования: вышеописанная общность ценностей, интересов, представлений о наиболее эффективном устройстве организационной деятельности и, собственно, схожесть самих организационных практик приводит к формированию единой «ценностной рамки» (Le Ber, Branzei 2010). И, что важно, у таких НКО возникает общая идентичность (Kreutzer, Jager 2011), на основе которой создаётся профессиональное сообщество третьего сектора. Его 
члены строго делят все НКО на «правильных своих»- «профессионалов» и «неправильных чужих»- «непрофессионалов».

Чаепитие в контексте российских НКО, оказывающих социальные услуги людям старшего возраста,- это та точка отсчета и форма деятельности, на отношении к которой строится идентичность тех, кто чувствует себя частью «профессионального сообщества» третьего сектора. Причин для этого, видимо, две. Во-первых, чаепитие- самая распространенная и, одновременно, «простая» форма социальных услуг. Во-вторых, чаепития имеют определенную идейную связь с представлениями о старении.

Первый аргумент исходит из того, что для оказания услуги в виде чаепития достаточно купить и заварить чай, пригласить гостей- нет необходимости изучать социальную работу в университете, выстраивать отношения с потенциальными грантодателями, учиться писать проектные заявки. При этом в тех случаях, когда «профессиональные НКО» все же организовывают чаепития, они стараются усложнить процесс оказания услуги. Например, приглашают психологов, просят участников подготовить идеи для встреч, организовывают театральное представление, выбирают еду к чаю с учетом советов медицинских работников. Лишь если встречи для чаепития будут описаны в категориях развития сообщества, представлены механизмы «устойчивости» (т.е. то, каким образом повысится социальный и культурный капитал людей старшего возраста, какие инициативные группы и проектные идеи могут возникнуть, какие навыки будут получены) - у грантовой заявки может появиться шанс в конкурсе.

Второй аргумент - «идеологический». Профессионалы третьего сектора видят чаепития как «посиделки с самоваром и сушками»-характерным примером «традиционной старости», которую сторонники активного старения не принимают. А профессиональные НКО в подавляющем большинстве выступают в поддержку активного старения; отдельные сотрудники могут иметь другие взгляды, но это не отражается на их работе, в которой они критикуют «традиционную» старость).

Обобщая, профессионализация НКО- это процесс «формализации и бюрократизации общественного движения или низовой инициативы» (Choudry, Kapoor 2013), в результате которого организация выдвигает претензию на статус экспертов в сфере своей деятельности и начинает ориентироваться на поддержание собственной деятельности вместо поддержки получателей её услуг. В случае профессионализации сразу нескольких организаций формируется сообщество со своим языком (Joutsenvirta 2011) и идентичностью (Shrestha 2002). Чаепитие среди НКО, занимающихся оказанием социальных услуг людям старшего возраста в Санкт-Петербурге, воспринимается как «базовая» форма заботы, наиболее простая- и оттогонеэффективная, т.е. не имеющая долгосрочного положительного влияния на жизни получателей заботы. Это связано и с образом традиционной 
старости в российском обществе, и с тем, что такая забота не требует особых, «экспертных», навыков.

Необходимо также отметить, что некоторые крупные «клиентелистские» (Cook, Vinogradova 2006) - зависимые от государства- НКО также могут иметь признаки профессионализации (бюрократизация, ориентация на поддержание деятельности). Однако в полной мере профессионализированными $\mathrm{HКO} \mathrm{с} \mathrm{точки} \mathrm{зрения} \mathrm{идентичности} \mathrm{и} \mathrm{ценностей} \mathrm{они} \mathrm{не} \mathrm{являются.} \mathrm{В} \mathrm{интервью}$ с представителями таких организаций не было отсылок к принадлежности к сообществу третьего сектора, строящегося на принципах идеологической приверженности идеалам «гражданского участия» и «демократии». Одновременно некоторые небольшие «низовые» организации (например, самоорганизовавшиеся ветеранские объединения) вполне могут быть зависимыми от государства и неформальных связей с представителями государственных органов, при этом, сохраняя «добровольческую идентичность» (Kreutzer, Jager 2011) и ориентацию на получателей услуг.

\section{Методология исследования}

Исследование, результаты которого нами представлены, выполнено в качественной парадигме. Данные собирались несколькими методами. Во-первых, это 48 полуструктурированных интервью с 50 информантами (в 15 из них в той или иной мере упоминается чай) длиной от получаса до двух с половиной часов. Основным критерием выбора информантов было значение конкретного человека в организации оказания социальных услуг (Antonsson et al. 2012:737). Всего состоялись беседы с 19 мужчинами и 31 женщиной в возрасте от 19 до 88 лет. Подавляющее большинство информантов имели высшее образование (за исключением двух получателей услуг и четверых «заботящихся» более молодого возраста). Всего интервью проводились с представителями 16 некоммерческих организаций. Организации отличались по типу: профессионализированные НКО (крупные благотворительные фонды, грантодатели, грантовые операторы, ресурсные центры); «клиентелистские» НКО- связанные с государством ветеранские организации; группы «самопомощи», выросшие из инициативных групп. Я также общался с представителями двух организаций, не имеющих официального статуса некоммерческих (неформальные добровольческие движения в социальных сетях). Выбор организации и информанта проводился методом снежного кома. Общая совокупность данных не ограничивается профессиональными НКО, а отражает разнообразие третьего сектора в Санкт-Петербурге. В отличие от профессионализированных НКО, другие организации не формируют сообщество и поэтому более атомизированы: не знают о существовании друг друга, не участвуют в совместных мероприятиях. Поэтому тактика снежного кома в их случае работала слабо, предпочтение отдавалось поиску организаций по принципу 
соответствия созданной категоризации петербургских НКО. Критериями для выбора организации стали степень зависимости от государства, уровень формализации, разнообразие социальных услуг, доступность для интервью сразу нескольких сотрудников.

Интервью транскрибировались дословно. На этапе анализа использовались конденсация и категоризация. Сначала выделялись доминирующие темы, затем их список дополнялся. Кодирование было описательным и, частично, интерпретативным, с последующим использованием «насыщенного описания» (Miles, Huberman 1994:54-58; Flick 2011: 152-154). Первый тип кодирования дал возможность построчного анализа тем, дискурсов и контекстов, а второй- позволил «приоткрыть завесу» «скрытых» смыслов. В свою очередь насыщенное описание позволило переложить обнаруженные темы и категории на язык социологической теории. Другими словами, данные сначала структурировались, а потом-осмыслялись.

Большая часть интервью проводилась в Петербурге, часть- в Ленинградской области. Дополнительным источником данных стал анализ документов и социальных сетей, предоставивший массу вторичных данных о различных мероприятиях и том, как они были организованы. Кроме того, существенный массив косвенных данных получен путём наблюдений (в основном, включённых - в роли преподавателя, участника застолий, добровольца), проводимых в различных условиях, пространствах и организациях: речь идёт о рутинной офисной работе, встречах с получателями социальных услуг, культурных мероприятиях, конференциях. Полевые наблюдения и интервью проводились в 2015 г. (особенно интенсивно- осенью).

\section{Дискурс о чаепитиях}

Часть петербургских НКО (их сотрудников) имеют профессионализированную идентичность «представителей некоммерческого сектора». Они оценивают успешность («эффективность») организации с точки зрения «умения писать грантовые заявки», наличия «навыков проектной деятельности», «устойчивости лучших практик». Главной целью их деятельности являются структурные социальные изменения либо поддержание собственной деятельности. Другая же часть не мыслит собственную деятельность в категориях проектной деятельности, не строит собственное функционирование вокруг грантовых конкурсов, не чувствует себя частью некого сообщества организаций, а целью своей деятельности видит помощь конкретным получателям услуг.

Многие из моих информантов, представляющих именно такие профессионализированные НКО, описывали себя через оппозицию «непрофессионализированным» клиентелистским организациям (зависимым от государства) и низовым группам самопомощи (по мнению профессионализированных «нкошников», недостаточно знающим и умеющим, чтобы 
считаться достаточно «полезными» для «признания» их принадлежности к сообществу третьего сектора). Такое внутреннее разделение среди НКО характерно для третьего сектора (Кондаков 2015).

Экспертное знание, навыки ведения проектов, внимание к «устойчивости» механизмов работы НКО-всё это, по мнению «профессионалов», отделяет «непрофессионалов» от сообщества третьего сектора. Стоит отметить, что идентичность- лишь одна составляющая отличий. Втораято, как дискурс о чаепитии влиял на практики заботы о людях старшего возраста. А именно - как часто организаторы заботы пили чай со своими получателями социальных услуг, а также с какой целью, и как чаепития понимались в контексте организационной деятельности.

Многие непрофессионализированные НКО делают чаепитие центральным элементом собственной регулярной деятельности. В этом случае чаепития являются одной из важнейших разновидностей культурных мероприятий, объединяющих самое большое количество получателей услуг одновременно. Для профессионализированных НКО чаепития- лишь дополнение к более сложным проектам- патронажу, развитию добровольчества среди людей старшего возраста, образовательным курсам. Чай регулярней и больше использовался в деятельности волонтёрских организаций, на периферии (например, дома престарелых в сельской местности) и в частных пространствах квартир и домов пенсионеров. Чем более профессионализированы были НКО и чем более официальны были мероприятия (конференции, встречи с государственными органами, экспертные советы), тем чаще доминирующим напитком был кофе. Понятие «кофе-брейка» применялось именно профессионализированными НКО, которые в своей деятельности часто используют «культурные пространства», «лофты» и другие «модные места» в Петербурге. Кофе-аппараты и тарелки с пластиковыми капсулами сливок- это то, что делало мероприятия таких организаций схожими с мероприятиями вроде бизнес-встреч и конференций.

Однако, обобщать и делать масштабные выводы о противопоставлении кофе чаю всё же нельзя. Скорее, это были ситуативные практики, зависимые от формата мероприятий. Лишь в некоторых случаях выбор кофеен вместо чайных был сознательным: так, НКО «Снежинка» проводит свои встречи с получателями услуг именно в кофейнях сознательно-в рамках собственной идеологии продвижения активного старения, которая на практике понимается в участии молодых пенсионеров в культурной жизни города, их путешествиях, занятиях спортом и гражданским активизмом. Совсем иная ситуация с употреблением чая сложилась в клиентелистских НКО и инициативных группах «самопомощи». Условия в этих организациях характеризуются скромностью и простотой. Обычно такие НКО расположены при государственных учреждениях муниципального уровня на окраинах города. Общая эстетика ежедневных практик клиентелистских и низовых НКО ближе к «советской», чем к «современной», характерной для профессионализированных НКО. 
Заваренный чай, что на мероприятиях профессионализированных НКО (где он выступал альтернативой кофе), что на мероприятиях «непрофессионалов», был в пакетиках. Заварка чая в чайнике, видимо, представляла собой слишком технологически сложный процесс, требующий дополнительных усилий. Отличия в качестве чая были незначительными, и, в основном, касались цены и бренда. Так, профессионализированные НКО, если использовали чай, то средней ценовой категории (условный «Greenfield»), чьи пакетики красиво бы смотрелись в плетённой корзинке на столах, покрытых скатертью, используемых для кофе-брейков (стоит отметить, что если мероприятия проводятся на внешней площадке, то ассортимент обычно предоставляется по умолчанию). В свою очередь ветеранские организации и группы самопомощи обычно более стеснены в финансах. Кроме того, не имея организационных предпочтений и строгой отчётности, такие НКО дают большую свободу выбора тем, кто занимается закупкой продуктов. Сотрудники (волонтёры) НКО покупают то, что имеется в ближайшем магазине и соответствует их-небогатых пенсионеров- привычкам. В результате условный стандартный чай на праздниках в «непрофессиональных НКО»- это чай марки «Майский».

Отличалась и частота употребления чая: ветеранские организации устраивают чаепития регулярно и по любому поводу. Число мероприятий там значительно превышает число «празднований» в «профессионализированных» НКО, где всё обычно ограничено Днём пожилого человека, 9 мая, закрытием очередного проекта и Новым Годом. Ветераны же празднуют ещё и День окончания блокады, дни памяти участников соответствующих вооружённых конфликтов, различные народные (Масленица) и православные (Пасха) праздники, дни рождения членов организации. Сами застолья также отличаются. Профессионализированные НКО разнообразят стол чуть более дорогими сладостями. «Непрофессионалы» выбирают выпечку нижней ценовой категории и еду домашнего приготовления, которую приносят члены организаций.

Стоит отметить, что несмотря на пренебрежительное отношение к чаепитиям, в 10 из $16 \mathrm{HКО} \mathrm{так} \mathrm{или} \mathrm{иначе} \mathrm{устраивают} \mathrm{«посиделки} \mathrm{с} \mathrm{чаем»}$ (независимо от принадлежности к сообществу третьего сектора). Различие именно в регулярности таких мероприятий и отношении к ним (соответственно, как к вспомогательному элементу проектной деятельности или же как к основной форме помощи пожилым).

\section{Чаепития и идентичность членов профессионального сообщества третьего сектора}

Чаепития имеют особые идеологические и культурные коннотации: чай воспринимается представителями профессионализированных НКО как чтото «традиционное», относящееся к «пассивному старению» как антитезе «активному старению»- доминирующей идеологии в среде профессиона- 
лизированных НКО, подразумевающей «культурную, социальную, экономическую и гражданскую активность людей старшего возраста» (WHO 2002):

Говорю: это бред! Мы должны наконец-то учиться менять концепции в головах у людей! Что это, говорю, за бабушка, которая пьёт чай из самовара, а? [Как так] можно? (Информант 4, женщина, около тридцати, проектный менеджер, преподаватель и заместитель директора профессионализированной НКО).

Сидящие за столом с самоваром напротив друг друга «баба с дедом»фольклорный образ. Нынешние «бабушки-в-платочке» (как противовес «пожилым дамам» из дискурса об активном старении) так же предпочитают чай. Такая дихотомия в дискурсе рождается из своеобразного фундаментального выбора между «традицией» и «современностью» (Низамова 2016). Под традицией понимается идеализированная семейная межпоколенческая забота, беспрекословный авторитет старшего по возрасту, уход за внуками, тихие и спокойные занятия вроде вязания шарфов. Такая модель необязательно критиковалась информантами, представляющими профессионализированные $\mathrm{HКO}$, но описывалась как устаревшая и невозможная. А под «современностью», в свою очередь, понимается активное старение, как старение свободное от семейных обязательств и ненаполненное болезнями, активное потребление различных услуг (например, салонов красоты), посещение культурных мероприятий, путешествия в другие страны, участие в волонтёрском движении.

Представители профессионализированного сообщества связывают пассивную старость (и чаепитие как её составляющую часть) с отсутствием развития третьего сектора, «гражданской сознательности» и низким желанием граждан участвовать в жизни сообества и государства в целом. В их понимании те организации, которые ограничивают себя чаепитиями, нерегулярной финансовой и материальной поддержкой- «ненастоящие». Как однажды в достаточно жёсткой форме пояснила одна из моих информантов«профессионалов», чаепития вне проектной деятельности- «бессмысленны». Поэтому чаепития- удел тех, «кто не имеет понимания приниипов и задач существования третьего сектора». Как она выразилась: «они слишком часто просто пьют чай, чтобы называться полноченньми НКО».

Схожих взглядов придерживался и директор одного из самых успешных и богатых благотворительных фондов в Санкт-Петербурге. В беседе с ним мы подробно затронули тему чаепития (как возможной потребности пожилых людей, которую как раз и необходимо удовлетворять). Информант признал, что для людей старшего возраста, возможно, интереснее приходить и пить чай, чем участвовать в каких-то сложных проектах, способствующих их гражданской активности. Но уточнил, как и его коллега ранее, «даже для того, чтобы прийти выпить чай нужна тренировка». Здесь имеется в виду то, что необходимы знания определённого контекста, 
наличие навыков, которые способствовали бы изменению поведения, потребностей и взглядов бенефициара в соответствии с задачами самих НКО. И вообще главной целью является не удовлетворение потребностей отдельных пенсионеров, а изменения на уровне общества.

При этом вышеупомянутый директор, как и многие другие представители профессионализированных НКО, признаёт, что одной из основных проблем для граждан пожилого возраста являются именно одиночество и социальная депривация, а чаепития позволяют их преодолеть. Однако «профессионализированные» участники исследования ставят такие совместные мероприятия на одну ступень с «посиделками на скамейках y nодъезда». И если социализация пожилых чаем и ограничивается, то это не лучший сценарий для развития третьего сектора и, как следствие, «гражданского самосознания» в России.

Итак, представители профессионализированных НКО категорически отказывались считать чаепитие чем-то способствующим «устойчивому росту благосостояния» и «развитию общества». Место чаепитий в дискурсе профессионализированных НКО занимают добровольчество, экскурсии за границу, гражданский активизм. Практическая же разница в том, что для профессионализированных НКО чаепитие инструментально и не является самоцелью. Зачастую, чаепития в НКО-членах сообщества третьего сектора организовываются по инициативе бенефициаров (т.е. пожилых людей). В свою очередь профессионализированные организаторы предпочитают кофе, как более подобающий напиток «людям активнылм», готовым «заниматься делами» и общественной работой, а не «сидеть на завалинке» и «доживать свои последние дни».

В случае же инициативных групп чаепития считаются нормой. Имея ограниченные ресурсы, такие НКО с трудом могут позволить себе походы в модные кофейни. Но и без финансового аспекта организаторов и участников полностью устраивают чаепития в офисах организаций. В отличие от профессионализированных НКО, низовые инициативные группы активно выкладывают фото-отчёты о чаепитиях в своих социальных сетях. Такие отчёты составляют значительную часть их мультимедийного визуального контента.

\section{Заключение}

Что следует из этой разницы в отношении к чаепитиям? Во-первых, разрыв, возникающий между профессионализированными НКО и интересами (потребностями) их бенефициаров (Krause 2014). Во-вторых, оказалось, что чаепитие дискурсивно включено в пример самой «неэффективной» и «негражданственной» деятельности третьего сектора. Спектр мнений здесь отличается, но чаепития, так или иначе, либо рассматриваются как самая простая форма взаимодействия между членами местного сообщества 
(не влияющее на общество в целом, на развитие социальных и политических институтов), либо как вовсе бесполезная трата времени и имитация деятельности. Так или иначе, пить чай в понимании профессионализированных представителей третьего сектора, означает воспроизводить пассивную«close to home» (Eliasoph 1997)- стратегию деполитизации, в противовес широкому инструментарию гражданского активизма, ведущего (потенциально) к изменениям на всех уровнях общества и государства.

Именно поэтому чаепитие воспринимается представителями профессионализированного третьего сектора как необходимая, но в целом негативная форма услуги пожилым людям. Да, чаепитие в краткосрочной перспективе решает проблему социальной депривации. Но «просто сидеть и пить чай с сушками» мало соотносится с представлениями профессионализированных НКО об устойчивом развитии третьего сектора и о решении социальных проблем. Поэтому чаепития не поощряются в рамках грантовых конкурсов или в деятельности самих профессионализированных негосударственных поставщиков социальных услуг. При этом чаепития имеют чёткие негативные коннотации. Во-первых, это упомянутая ассоциация с клиентелистскими НКО, которые представляют собой (с точки зрения профессионализированных НКО) институты авторитарного государства, незаинтересованного в сильном и независимом третьем секторе. А, во-вторых, чаепитие воспринимается как характерный пример старения как «дожития», т.е. болезненного и экономически трудного времени, когда человек (само)устраняется от общественной, культурной, экономической и политической жизни. В этом смысле домашние чаепития противопоставляются образу молодого пенсионера и чашке кофе в общественных местах.

Совмещение обеих негативных коннотаций привело к тому, что отношение к чаепитиям, их использование в рамках взаимодействия с пожилыми получателями заботы, для российского профессионализированного сообщества третьего сектора стало маркером негражданственности, неэффективности деятельности и одним из ключевых символов «авторитарности» и «консервативности». Соответственно, негативное отношение к чаепитиям и критика этой практики явилась важной составляющей идентичности профессионализированного сообщества третьего сектора в Петербурге.

Однако то, в какой степени эта ассоциация устойчива, насколько она характерна для профессионализированных НКО, не занимающихся вопросами старения и поддержки пожилых бенефициаров, существует ли антагонизм между чаем и кофе в контексте дискуссий о развитии гражданского общества в России и какое место отводится чаю в идеологиях, направленных на сохранение авторитарного режима,- всё это вопросы для дальнейших исследований. Остаётся лишь надеется, что данная статья послужит толчком для более пристального внимания к практикам потребления чая, как в контексте изучения демократизации в России (и других странах), так и в контексте социологии повседневности. 


\section{Список источников}

Бабинцев В.П. (2014) Бюрократизация регионального вуза. Высшее образование в России, (2): 30-37.

Кондаков А.А. (2015) Возможности взаимодействия между акторами в миграционной политике России. Журнал соџиологии и сощииальной антропологии, 18 (4): 174-186.

Низамова А.Н. (2016) Активное долголетие и внешний вид: как теоретическая концепция регулирует самовосприятие в старшем возрасте? Журнал исследований социальной политики, 14 (4): 569-582.

Antonsson H., Korjonen S. E., Rosengren K. (2012) First-Line Managers' Experiences of Alternative Modes of Funding in Elderly Care in Sweden. Journal of Nursing Management, 20 (6): 737-747.

Batley R. (2011) Structures and Strategies in Relationships between Non-Government Service Providers and Governments. Public Administration and Development, 31 (4):306-319.

Choudry A., Kapoor D. (2014) NGOization: Complicity, Contradictions and Prospects. Chicago: University of Chicago Press.

Cook L. J., Vinogradova E. V. (2006) NGOs Civic Society and Social Policy in Russia's Regions. Washington D.C.: The National Council for Eurasian and East European Research (Title VIII Program).

Eliasoph N. (1997) Close to Home: The Work of Avoiding Politics. Theory and Society, (26): 605-647.

Eliasoph N. (2011) Making Volunteers: Civic Life after Welfare's End. Princeton: Princeton University Press.

Flick U. (2011) Introducing Research Methodology: A Beginner's Guide to Doing a Research Project. Washington D. C.: Sage.

Jalali R. (2013) Financing Empowerment? How Foreign Aid to Southern NGOs and Social Movements Undermines Grass-Roots Mobilization. Sociology Compass, 7 (1): 55-73.

Joutsenvirta M. (2011) Setting Boundaries for Corporate Social Responsibility: Firm-NGO Relationship as Discursive Legitimation Struggle. Journal of Business Ethics, 102 (1):57-75.

King D. (2016) Becoming Business-Like: Governing the Nonprofit Professional. Nonprofit and Voluntary Sector Quarterly, 46 (2):241-260.

Krause M. (2014) The Good Project: Humanitarian Relief NGOs and the Fragmentation of Reason. Chicago: Chicago University Press.

Kreutzer K., Jäger P.U. (2010) Volunteering Versus Managerialism: Conflict Over Organizational Identity in Voluntary Associations. Nonprofit and Voluntary Sector Quarterly, 40 (4): 634-661.

Le Ber M. J., Branzei O. (2010) Value Frame Fusion in Cross Sector Interactions. Journal of Business Ethics, (94): 163-195.

Maier F., Meyer M., Steinbereithner M. (2016) Nonprofit Organizations Becoming BusinessLike: A Systematic Review. Nonprofit and Voluntary Sector Quarterly, 45 (1): 64-86. 
Miles M. B., Huberman A. M. (1994) Qualitative Data Analysis (2nd edition). Thousand Oaks: Sage Publications.

Nightingale A. J. (2005) 'The Experts Taught Us All We Know': Professionalisation and Knowledge in Nepalese Community Forestry. Antipode, (37):581-604.

Petrescu D. (2000) Civil Society in Romania: From Donor Supply to Citizen Demand. In: M. Ottaway, T. Carothers (eds.) Funding Virtue: Civil Society Aid and Democracy Promotion. Washington D. C.: Carnegie Endowment for International Peace: 217-240.

Salamon L. (1999) The Nonprofit Sector at a Crossroads: The Case of America. Voluntas, (10): 5-23.

Scheba A., Mustalahti I. (2015) Rethinking 'Expert' Knowledge in Community Forest Management in Tanzania. Forest Policy and Economics, (60): 7-18.

Shrestha C.H. (2002) NGOs as Thekadar or Sevak: Identity Crisis in Nepal's Non-Governmental Sector. European Bulletin of Himalayan Research, (22): 5-36.

Shrestha C.H., Adhikari R. (2011) NGOization and De-NGOization of Public Action in Nepal: The Role of Organizational Culture in Civil Society Politicality. Journal of Civil Society, 7 (1): 41-61.

WHO (2002) Health and Ageing. A Discussion Paper. Geneva: World Health Organisation. 
Arturs Holavins

\title{
ATTITUDES TOWARD TEA-DRINKING AS AN INDICATOR FOR THE PROFESSIONALIZATION OF THE THIRD SECTOR IN SAINT PETERSBURG
}

\begin{abstract}
The article discusses the culture of tea-drinking (tea parties) among the elderly population, as well as how non-governmental organisations offer such services in Russia from a perspective of third sector professional community identitybuilding. The main question of the research concerns how tea party culture is framed within the context of ideological and discursive debate about active ageing and the third sector development in Russia. Based on sociological qualitative empirical fieldwork research into non-governmental elderly care, I provide arguments on the connection between negative attitude towards drinking of tea and the professionalization of NGOs. As a result, what is found is that negative attitudes toward tea-drinking social service have become a key shared value in the process of identity-building within the third sector community of Saint Petersburg NGOs. The fieldwork includes semistructured interviews, participatory observations and a documentary analysis of the activities of 16 elderly care social service provision-involved third sector organizations in Saint Petersburg, the second largest city in Russia. I argue that tea partying has become an oppositional point of reference for professional NGOs, associated with 'inefficiency', 'unsustainability' and 'worthlessness', all of which, from the perspective of professional third sector community, prevents development of civil society and 'civic culture' development in Russia. Consequently, tea-drinking is one of the most widespread yet heavily debated social activities. Attitudes towards tea-drinking differ among professionalised NGOs' representatives and employees of grassroots, clientelist organizations and other non-members of the community. In the concluding part, I raise several possible topics for further research of tea drinking practices regarding civil society development and beyond.
\end{abstract}

Key words: tea party, NGOs, Russia, NGO-ization, identity-building

DOI: $10.17323 / 727-0634-2020-18-1-99-114$

\section{References}

Antonsson H., Korjonen, S.E., Rosengren K. (2012) First-Line Managers' Experiences of A1ternative Modes of Funding in Elderly Care in Sweden. Journal of Nursing Management, 20 (6): 737-747.

Babintsev V.P. (2014) Bjurokratizacija Regional'nogo Vuza [Bureaucratisation of a regional university]. Vysshee obrazovanie v Rossii [Higher Education in Russia], (2): 30-37.

Batley R. (2011) Structures and Strategies in Relationships between Non-Government Service Providers and Governments. Public Administration and Development, 31 (4):306-319.

Arturs Holavins - M. Sc.Pol., Ph.D. candidate at the University of Helsinki, Finland. Email: arturs.holavins@helsinki.fi 
Choudry A., Kapoor D. (2014) NGOization: Complicity, Contradictions and Prospects. Chicago: University of Chicago Press.

Cook L. J., Vinogradova E. V. (2006) NGOs Civic Society and Social Policy in Russia's Regions. Washington D.C.: The National Council for Eurasian and East European Research (Title VIII Program).

Eliasoph N. (1997) Close to Home: The Work of Avoiding Politics. Theory and Society, (26): 605-647.

Eliasoph N. (2011) Making Volunteers: Civic Life after Welfare's End. Princeton: Princeton University Press.

Flick U. (2011) Introducing Research Methodology: A Beginner's Guide to Doing a Research Project. Washington D. C.: Sage.

Jalali R. (2013) Financing Empowerment? How Foreign Aid to Southern NGOs and Social Movements Undermines Grass-Roots Mobilization. Sociology Compass, 7 (1):55-73.

Joutsenvirta M. (2011) Setting Boundaries for Corporate Social Responsibility: Firm-NGO Relationship as Discursive Legitimation Struggle. Journal of Business Ethics, 102 (1): 57-75.

King D. (2016) Becoming Business-Like: Governing the Nonprofit Professional. Nonprofit and Voluntary Sector Quarterly, 46 (2): 241-260.

Kondakov A. (2015) Vozmozhnosti vzaimodejstvija mezhdu aktorami v migracionnoj politike Rossii [Possibilities of Interaction between Migration Policy Actors in Russia]. Žurnal sociologii i social'noj antropologii [Journal of Sociology and Social Anthropology], 18 (4): 174-186.

Krause M. (2014) The Good Project: Humanitarian Relief NGOs and the Fragmentation of Reason. Chicago: Chicago University Press.

Kreutzer K., Jäger P.U. (2010) Volunteering Versus Managerialism: Conflict Over Organizational Identity in Voluntary Associations. Nonprofit and Voluntary Sector Quarterly, 40 (4): 634-661.

Le Ber M. J., Branzei O. (2010) Value Frame Fusion in Cross Sector Interactions. Journal of Business Ethics, (94): 163-195.

Maier F., Meyer M., Steinbereithner M. (2016) Nonprofit Organizations Becoming BusinessLike: A Systematic Review. Nonprofit and Voluntary Sector Quarterly, 45 (1): $64-86$.

Miles M. B., Huberman A. M. (1994) Qualitative Data Analysis ( $2^{\text {nd }}$ edition). Thousand Oaks: Sage Publications.

Nightingale A.J. (2005) 'The Experts Taught Us All We Know': Professionalisation and Knowledge in Nepalese Community Forestry. Antipode, (37):581-604.

Nizamova A. (2016) Aktivnoe Dolgoletie i Vneshniy Vid: Kak Teoreticheskaya Kontseptsiya Reguliruet Samovospriyatie v Starshem Vozraste [Active Ageing and Outward Appearance: How Do Theoretical Conceptions Affect Self-Perception in Old Age?]. Journal of Social Policy Studies, 14 (4): 569-582.

Petrescu D. (2000) Civil Society in Romania: From Donor Supply to Citizen Demand. In: M. Ottaway, T. Carothers (eds.) Funding Virtue: Civil Society Aid and Democracy Promotion. Washington D. C.: Carnegie Endowment for International Peace: 217-240.

Salamon L. (1999) The Nonprofit Sector at a Crossroads: The Case of America. Voluntas, (10): $5-23$.

Scheba A., Mustalahti I. (2015) Rethinking 'Expert' Knowledge in Community Forest Management in Tanzania. Forest Policy and Economics, (60): 7-18.

Shrestha C.H. (2002) NGOs as Thekadar or Sevak: Identity Crisis in Nepal's Non-Governmental Sector. European Bulletin of Himalayan Research, (22):5-36.

Shrestha C.H., Adhikari R. (2011) NGOization and De-NGOization of Public Action in Nepal: The Role of Organizational Culture in Civil Society Politicality. Journal of Civil Society, 7 (1): 41-61.

WHO (2002) Health and Ageing. A Discussion Paper. Geneva: World Health Organisation. 